\title{
Ribonucleic Acid Synthesis in Cells Infected with Herpes Simplex Virus
}

I. Patterns of Ribonucleic Acid Synthesis in Productively Infected Cells

\author{
EDWARD K. WAGNER AND BERNARD ROIZMAN \\ Department of Microbiology, University of Chicago, Chicago, Illinois 60637
}

\section{Received for publication 10 February 1969}

\begin{abstract}
HEp-2 cells were pulse-labeled at different times after infection with herpes simplex virus, and nuclear ribonucleic acid (RNA) and cytoplasmic RNA were examined. The data showed the following: (i) Analysis by acrylamide gel electrophoresis of cytoplasmic RNA of cells infected at high multiplicities [80 to 200 plaque-forming units (PFU)/cell] revealed that ribosomal RNA (rRNA) synthesis falls to less than $10 \%$ of control (uninfected cell) values by $5 \mathrm{hr}$ after infection. The synthesis of $4 S$ RNA also declined but not as rapidly, and at its lowest level it was still $20 \%$ of control values. At lower multiplicities (20 PFU), the rate of inhibition was slower than at high multiplicities. However, at all multiplicities the rates of inhibition of $18 S$ and $28 S$ rRNA remained identical and higher than that of $4 S$ RNA. (ii) Analysis of nuclear RNA of cells infected at high multiplicities by sucrose density gradient centrifugation showed that the synthesis and methylation of $45 S$ rRNA precursor continued at a reduced but significant rate (ca. $30 \%$ of control values) at times after infection when no radioactive uridine was incorporated or could be chased into $28 S$ and $18 S$ rRNA. This indicates that the inhibition of rRNA synthesis after herpesvirus infection is a result of two processes: a decrease in the rate of synthesis of $45 S$ RNA and a decrease in the rate of processing of that $45 S$ RNA that is synthesized. (iii) Hybridization of nuclear and cytoplasmic RNA of infected cells with herpesvirus DNA revealed that a significant proportion of the total viral RNA in the nucleus has a sedimentation coefficient of $50 S$ or greater. The sedimentation coefficient of virus-specific RNA associated with cytoplasmic polyribosomes is smaller with a maximum at $16 S$ to $20 S$, but there is some rapidly sedimenting RNA ( $>28 S$ ) here too. (iv) Finally, there was leakage of low-molecular weight (4S) RNA from infected cells, the leakage being approximately threefold that of uninfected cells by approximately $5 \mathrm{hr}$ after infection.
\end{abstract}

Herpes simplex virus profoundly alters the macromolecular metabolism of infected cells. Host deoxyribonucleic acid (DNA) synthesis comes to a halt (2; Schwartz, Roizman, and Sydiskis, in preparation), and host polyribosomes become disaggregated marking the end of host protein synthesis (26). The ribonucleic acid (RNA) metabolism of infected cells has been examined in several laboratories and the following facts are known.

(i) Roizman et al. (18), Aurelian and Roizman (1), Hay et al. (11), and Flanagan (8) have shown an overall decline in the rate of RNA synthesis early after infection, followed by a leveling off in rate from about 3 to $8 \mathrm{hr}$ after infection, and then a slow irreversible decline.

(ii) Hay et al. (11) analyzed extracts of cells labeled for $30 \mathrm{~min}$ and centrifuged in sucrose density gradients. They concluded that in infected cells the synthesis of RNA greater than $28 S$ progressively declines. However, the 30-min labeling interval is insufficient to allow the complete processing of ribosomal RNA (rRNA) from its high-molecular-weight nuclear precursors into cytoplasmic $28 S$ and $18 S$ rRNA (4). In addition, the fractionation of total cellular RNA does not show whether there are any interruptions of the transport of the processed $28 S$ and $18 S$ rRNA from the nucleus to the cytoplasm in the manner analogous to that reported in poliovirus-infected cells (15) and in the cells treated with vinca alkaloids (28). Flanagan (8) also fractionated whole cell extracts by sucrose density gradient centrifugation after 15-min pulses with radioactive uridine at various times after infection and reported a decline in the synthesis of high-molecular-weight RNA at various times after infection. Again, these experiments do not shed light on the details of the inhibition of rRNA synthesis for the reasons given above. 
(iii) The synthesis of virus-specific RNA has teen detected by both Hay et al. (11) and by Flanagan (8). Flanagan found, in infected KB cells, virus-specific RNA with sedimentation coefficients ranging from $12 S$ to at least $32 S$ with the major portion sedimenting at about 12 to $24 S$, whereas Hay and co-workers found, in BHK-21 cells, virus-specific RNA with a sedimentation coefficient of $20 S$ although they did not, apparently, examine RNA sedimenting more rapidly. Neither paper, however, demonstrated that the virus-specific material is associated with polyribosomes or, indeed, that it is found in the cytoplasm of infected cells.

(iv) Hay et al. (11) and Flanagan (8) showed that there is a decline in the amount of slowly sedimenting RNA (4 to $5 S$ ) synthesized in host cells after infection, and the former workers concluded that this is indicative of an inhibition of $4 S$ RNA synthesis after infection by herpes simplex virus. Subsequently, workers in SubakSharpe's laboratory $(12,23,24)$ reported, in contrast to the findings of Flanagan (11), the presence of $4 S$ RNA in infected cells which anneals to viral DNA and of a species of arginyl transfer RNA (tRNA) with properties different from corresponding uninfected cell arginyl tRNA. However, evidence showing that the arginyl tRNA present in infected cells anneals with viral DNA has not been furnished. It must also be noted that the radioactivity found at the top of sucrose density gradients after fractionation of cell lysates labeled by short pulses of uridine is not confined exclusively or even in large part to tRNA, since small species of messenger RNA (mRNA) and even very small oligonucleotides which co-precipitate with higher molecular weight RNA can be found in this region $(28,31)$.

This paper deals primarily with (i) the patterns of inhibition of nuclear and cytoplasmic RNA synthesis, (ii) the processing of rRNA in infected cells, and (iii) the size distribution of RNA hybridizable to viral DNA in the nucleus and cytoplasmic polyribosomes of infected cells. Subsequent papers in this series will deal with tRNA synthesis and with the time of synthesis and processing of viral RNA in herpesvirus-infected cells.

\section{MATERIALS AND METHODS}

Solutions. Reticulocyte standard buffer (RSB) was prepared according to Warner et al. (29), phosphatebuffered saline (PBS) was prepared according to Dulbecco and Vogt (6), and high-salt buffer was prepared according to Penman (15). SSC contained 0.15 $\mathrm{M}$ sodium chloride and $0.015 \mathrm{M}$ sodium citrate.

Cells and media. Human epidermoid carcinoma no. 2 (HEp-2) cells were grown in monolayers in Eagle minimal essential medium (EMEM; 7) containing $10 \%$ calf serum. Details of the growth and properties of HEp- 2 cells have been described previously $(1,17)$.
Virus and infection. The MPdk- strain of herpes simplex virus was used in all experiments (17). Rapidly growing and dividing cells were infected by exposure, at $37 \mathrm{C}$ for $1 \mathrm{hr}$, to sufficient virus in mixture 199 supplemented with $1 \%$ calf serum to yield multiplicities ranging from 10 to 200 plaque-forming units (PFU) per cell as needed. The residual inoculum was then removed; the cells were rinsed with warm medium and incubated at $37 \mathrm{C}$ in a maintenance medium consisting of $1 \%$ dialyzed calf serum, nonessential amino acids, essential amino acids, and vitamins at twice the concentration recommended by Eagle (7). Elapsed time after infection was calculated from the time of addition of maintenance medium.

Radioactive labeling. At times after infection discussed below, the maintenance medium was aspirated and replaced with medium containing ${ }^{3} \mathrm{H}$-uridine (5 to $10 \mu \mathrm{c} / \mathrm{ml}$, specific activity $10 \mathrm{c} / \mathrm{mmole}$; Schwarz BioResearch, Orangeburg, N.Y.). At the end of the pulse, the radioactive medium was removed, and the cells were either harvested immediately by scraping into crushed, frozen PBS containing $10^{-4} \mathrm{M}$ unlabeled uridine or were harvested after additional incubation in fresh maintenance medium containing $10^{-4} \mathrm{M}$ unlabeled uridine.

Extraction of cytoplasmic RNA. Cells were suspended in RSB and were lysed either by breaking in a tight-fitting glass Dounce homogenizer calibrated to break no more than 1 to $2 \%$ of nuclei or by the addition of sufficient Nonidet P-40 (Shell Chemical Co.; 3) to make $0.5 \%$. The nuclei and cytoplasm were separated by low-speed centrifugation. The details of the extraction of cytoplasmic RNA and its fractionation are given in the legends to the figures.

Extraction and fractionation of nuclear RNA. Nuclei were obtained from infected or uninfected cells suspended in $0.5 \%$ Nonidet P-40 in RSB. They were then collected by low-speed centrifugation, lysed in highsalt buffer, digested with electrophoretically purified deoxyribonuclease (Schwarz BioResearch), and extracted with hot phenol and sodium dodecyl sulfate (SDS) by the method of Scherrer and Darnell (21) at $55 \mathrm{C}$. The details of the fractionation of nuclear extracts are given in the legends to the appropriate figures.

Preparation of herpesvirus DNA and DNA-RNA hybridization. Cultures of approximately $5 \times 10^{8}$ cells in cylindrical roller bottles $(10$ by $40 \mathrm{~cm})$ were infected as described by Roizman and Spear (19). After $24 \mathrm{hr}$ of incubation at $34 \mathrm{C}$, the cells were shaken off the glass and collected by centrifugation. The cells were then swollen in 10 volumes of deionized water, lysed with 20 strokes of a tight fitting Dounce homogenizer, and, after brief sonic treatment, centrifuged at 2,000 $\times$ $g$ for $10 \mathrm{~min}$. The supernatant fluid was then centrifuged at $20,000 \times g$ for $1 \mathrm{hr}$. The pellet contained 90 to $95 \%$ of the infectious virus. DNA was extracted from the pellet by digestion for 2 to $3 \mathrm{hr}$ at $37 \mathrm{C}$ with 25 to 50 volumes of a solution adjusted to $p \mathrm{H} 8$ and containing $1 \%$ SDS, $0.15 \mathrm{M}$ sodium chloride, $0.05 \mathrm{M}$ ethylenediaminetetraacetic acid, and $0.1 \%$ heat-inactivated Pronase (Calbiochem). The digestion was followed by repeated extraction with chloroform containing $2 \%$ isoamyl alcohol. The DNA was precipitated with 2 volumes of ethyl alcohol and collected 
by winding on a glass rod when no denatured protein could be seen at the chloroform-water interphase. The DNA was dissolved in one-half the original volume of $0.1 \times$ SSC and digested for $1 \mathrm{hr}$ at $37 \mathrm{C}$ with $50 \mu \mathrm{g}$ of heat-inactivated pancreatic ribonuclease per $\mathrm{ml}$. The DNA solution was then adjusted to $1 \times$ SCC and was extracted first with redistilled phenol at $55 \mathrm{C}$ and then several times with chloroform containing $2 \%$ isoamyl alcohol. The final material was usually precipitated with ethyl alcohol, collected by centrifugation, and redissolved in $0.1 \times \mathrm{SSC}$ to a final concentration of about 100 to $200 \mu \mathrm{g} / \mathrm{ml}$.

The DNA obtained in this manner contained 40 to $60 \%$ viral DNA as determined by isopycnic centrifugation in $\mathrm{CsCl}$ and by fractionation on methylated albumin-kieselguhr (MAK) columns prepared by the method of Sueoka and Cheng (25) with an 0.2 to 0.7 M $\mathrm{NaCl}$ gradient. Herpes simplex virus DNA was eluted from MAK columns with 0.37 to $0.4 \mathrm{M} \mathrm{NaCl}$, a concentration of $\mathrm{NaCl}$ similar to that required to elute equine abortion virus DNA (14). The DNA used for RNA hybridization was finally purified either from the first isopycnic centrifugation in $\mathrm{CsCl}$ solutions or from MAK chromatography by another isopycnic centrifugation in $\mathrm{CsCl}$ solution. Viral DNA collected after centrifugation was dialyzed for 48 to $60 \mathrm{hr}$ against four to five changes of 1,000 volumes of $0.1 \times \mathrm{SSC}$ at $4 \mathrm{C}$, diluted to 10 to $20 \mu \mathrm{g} / \mathrm{ml}$, and stored at $-20 \mathrm{C}$.

DNA-RNA hybridization was done by the method of Gillespie and Spiegelman (9). Viral DNA in $0.1 \times$ SSC was denatured by heating at a concentration of 1 to $2 \mu \mathrm{g} / \mathrm{ml}$ for 10 to $15 \mathrm{~min}$ at $100 \mathrm{C}$ followed by rapid cooling in an ice-salt bath. The solution containing the DNA was adjusted to a final concentration of $4 \times$ SSC, and samples containing $2 \mu \mathrm{g}$ of DNA were immobilized on 25-mm HA membrane filters (Millipore Corp., Bedford, Mass.) presoaked for 1 to $2 \mathrm{hr}$ in $4 \times$ SSC by slow filtration. Experiments with radioactive DNA showed that $99 \%$ of the DNA was retained on the filter under these conditions. The filter discs were dried for 2 to 3 $\mathrm{hr}$ in air and then for $6 \mathrm{hr}$ at $80 \mathrm{C}$. The discs were then soaked in $4 \times$ SSC and incubated with the DNA side up for 20 to $22 \mathrm{hr}$ at $67 \mathrm{C}$ in the bottom of glass scintillation vials containing $1 \mathrm{ml}$ of $4 \times$ SSC with radioactive RNA being tested for hybridization. The discs were then washed at least four times with 10-ml amounts of $2 \times \mathrm{SSC}$, incubated for $1 \mathrm{hr}$ at room temperature in $5 \mathrm{ml}$ of $2 \times$ SSC containing heat-inactivated pancreatic ribonuclease $(50 \mu \mathrm{g} / \mathrm{ml})$, rinsed two more times with 10-ml samples of $2 \times$ SSC, and then soaked for 2 to $3 \mathrm{hr}$ in 25 to $50 \mathrm{ml}$ of $2 \times$ SSC. The discs were then soaked for $15 \mathrm{~min}$ in $75 \%$ ethyl alcohol and dried in an oven at $60 \mathrm{C}$. Tritium disintegrations were counted in a Packard scintillation spectrophotometer. Blank discs or discs loaded in the same fashion with Bacillus subtilis DNA retained less than $0.01 \%$ of the input radioactivity after such treatment. Discs containing $2 \mu \mathrm{g}$ of viral DNA retained no more radioactivity than did blank discs when incubated with 400,000 counts/min of ${ }^{3} \mathrm{H}-\mathrm{RNA}$, obtained ky phenol extraction of the nuclei of uninfected HEp-2 cells labeled for $1 \mathrm{hr}$ in $10 \mu \mathrm{c}$ of ${ }^{3} \mathrm{H}$-uridine per $\mathrm{ml}$ of medium.

\section{RESULTS}

Cytoplasmic RNA. Several experiments were done to measure the effects of infection on the appearance of different classes of RNA in the cytoplasm. In one experiment, replicate cultures of $5 \times 10^{6} \mathrm{HEp}-2$ cells were infected with a multiplicity of 200 PFU. At times after infection indicated in Fig. 1 the cells were incubated for 30 min with medium containing ${ }^{3} \mathrm{H}$-uridine $(7 \mu \mathrm{c} /$ $\mathrm{ml}$ ). The label was then chased by incubating the cells in fresh medium containing $10^{-4} \mathrm{M}$ unlabeled uridine for an additional $2 \mathrm{hr}$. The cells were harvested, and the cytoplasmic RNA was extracted by the hot phenol-SDS method (21) and subjected to polyacrylamide gel electrophoresis along with and uninfected control sample treated in the same way.

The profiles of the radioactivity and optical density of the RNA in the acrylamide gels are shown in Fig. 1. The specific activity of the different classes of the RNA normalized with respect to the specific activity of the RNA of uninfected cells is shown in Fig. 2 . The results of this experiment were as follows. (i) With one exception, the appearance in the cytoplasm of all classes of RNA decreased after infection. The exception was polydisperse RNA larger than $28 S$ rRNA. The specific activity of this RNA in the cytoplasm increased three- four-fold after infection. (ii) The specific activity of $18 S$ and $28 S$ rRNA decreased at the same rate and leveled off at approximately $10 \%$ of the uninfected cell value between 5 and $9 \mathrm{hr}$ after infection. (iii) The specific activity of $4 S$ RNA was also diminished, but not nearly as much as that of rRNA.

To determine the effects of the multiplicity of infection on the specific activity of host RNA, the experiment was repeated with cells infected with multiplicities of 20 and 80 PFU per cell, respectively. The multiplicity of infection determined the rate of decrease in the specific activity of cytoplasmic rRNA and $4 S$ RNA (Fig. 3). However, the difference between the effects on cells infected with 80 and 200 PFU per cell was less pronounced than that between cells infected with 20 and 80 PFU per cell, respectively. The effects of the multiplicity of infection on the appearance of $4 S$ RNA and rRNA in the cytoplasm were approximately the same.

Several other experiments were carried out to determine the effect of different experimental conditions on the specific activity of cytoplasmic RNA.

(i) The labeling period was varied from 15 to $45 \mathrm{~min}$, and the chase was varied from 0 to $2 \mathrm{hr}$. The specific activity of the $18 S$ and $28 S$ rRNA declined at identical rates but more rapidly than that 


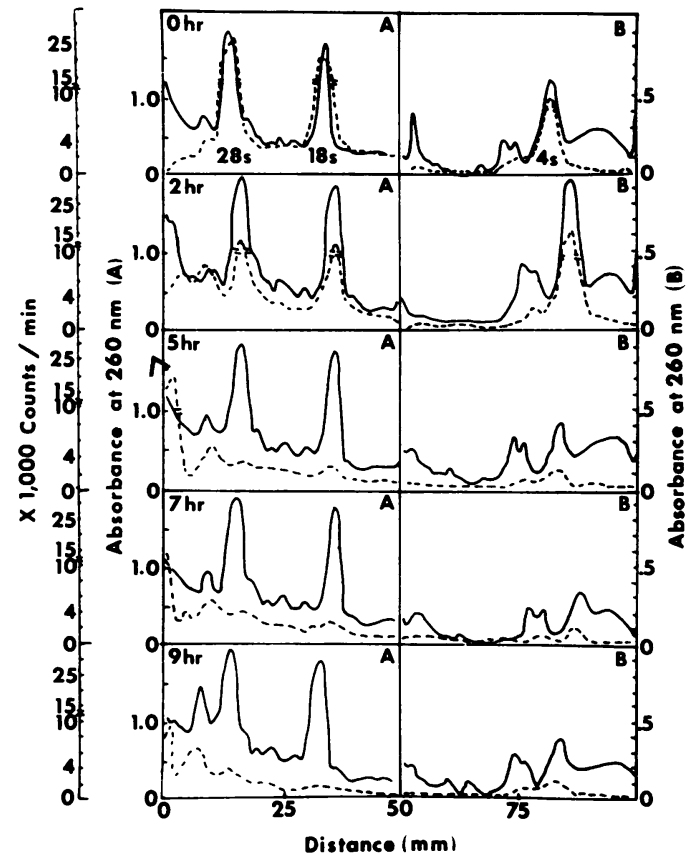

FIG. 1. Synthesis of cytoplasmic RNA in HEp-2 cells infected with herpes simplex virus. Cultures of $5 \times 10^{6} \mathrm{HEp}-2$ cells were infected at a multiplicity of $200 \mathrm{PFU} / \mathrm{cell}$ and were incubated for $30 \mathrm{~min}$, at the times shown, in medium containing ${ }^{3} \mathrm{H}$-uridine $(10 \mu \mathrm{c})$ $\mathrm{ml}$ ) and then for $2 \mathrm{hr}$ in medium containing $10^{-4}$ м unlabeled uridine. The cytoplasm obtained by centrifugation of the Dounce homogenate was extracted with hot phenol and SDS by the method of Scherrer and Darnell (21), except that the temperature of extraction was $45 C$. The cytoplasmic RNA was subjected to polyacrylamide gel electrophoresis (30) on 10-cm gels consisting of two segments, $5 \mathrm{~cm}$ in length, of $2.7 \%(A)$ and $5.5 \%$ $(B)$ acrylamide, respectively. The gels were monitored for optical density at $260 \mathrm{~nm}$ (solid line) and radioactivity (dashed line) as described previously (28).

of the $4 S$ RNA (Table 1). Cytoplasmic extracts obtained with Nonidet P-40 instead of Dounce homogenization yielded the same results.

(ii) The increase in the amount of $>28 S$ heterodisperse cytoplasmic RNA found in infected cells fractionated by Dounce homogenization (Fig. 1) was also present, albeit in reduced amount (one-third) in the cytoplasm of infected cells extracted with Nonidet P-40. The increased specific activity of this material could, in part, be due to nuclear breakage in cells infected for $5 \mathrm{hr}$ and longer. Breakage of nuclei cannot be, however, the sole explanation for this increase since the use of Nonidet P-40 results in less than $1 \%$ broken nuclei (unpublished data) and the nuclei do not greatly increase in fragility until about 10 hr post-infection (22). The possibility of nuclear

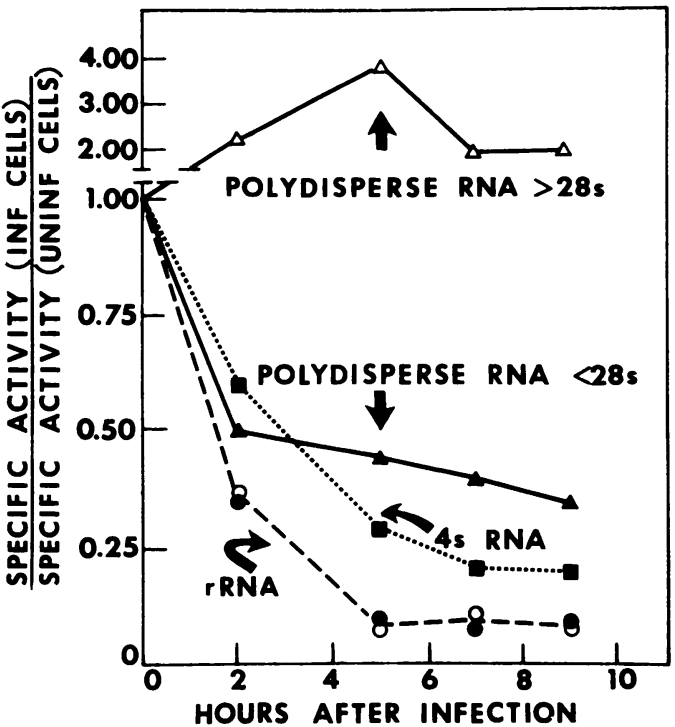

FIG. 2. Relative synthesis of various classes of cytoplasmic RNA in herpesvirus-infected HEp-2 cells. The relative specific radioactivity of $r R N A(28 S$, closed circles; 18S, open circles) and $4 S R N A$ (closed squares) was computed from the area under the corresponding optical density and radioactivity peaks of Fig. 1 and compared to the values for the uninfected control culture. The recovery of radioactivity of the polydisperse $R N A$ was corrected for the recovery of $r R N A$ in the corresponding cultures and also compared to values of the uninfected control.

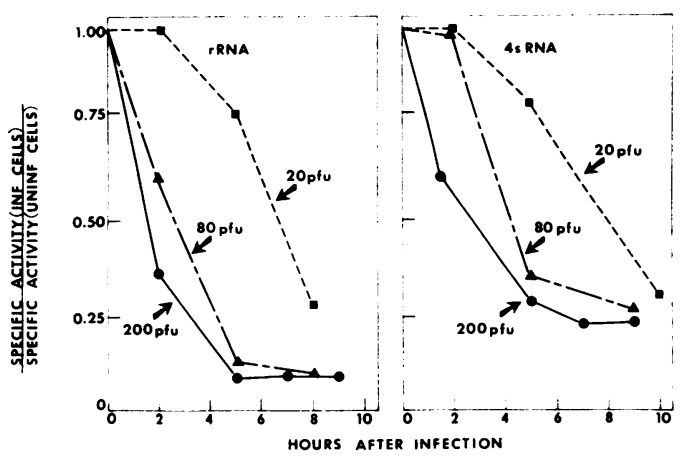

FIG. 3. Effect of multiplicity of infection on the inhibition of $r R N A$ and $4 S R N A$ synthesis in $H E p-2$ cells. Cultures of $5 \times 10^{6}$ cells were infected at multiplicities of 80 PFU (triangles) and 20 PFU (squares) and incubated at $37 \mathrm{C}$. At the times shown, the cells were pulsed for 20 min with ${ }^{3} \mathrm{H}$-uridine and then incubated for $90 \mathrm{~min}$ in fresh medium containing $10^{-4} \mathrm{M}$ unlabeled uridine. The cytoplasmic RNA was extracted and fractionated as described in the legend to Fig. 1 . The relative specific radioactivity of the $r R N A$ (average of both $28 S$ and $18 S$ ) and $4 S$ RNA was also calculated as descrihed in the legend to Fig. 1. 
TABLE 1. Relationship between the duration of the pulse of ${ }^{3} \mathrm{H}$-uridine and the residual $4 S$ and $r R N A$ synthesis in infected $\mathrm{HEp}-2$ cells ${ }^{a}$

\begin{tabular}{|c|c|c|c|c|c|c|c|}
\hline \multirow{2}{*}{ Expt } & \multirow{2}{*}{$\begin{array}{c}\text { Time pulsed } \\
\text { after } \\
\text { infection }\end{array}$} & \multicolumn{3}{|c|}{$\begin{array}{l}\text { Counts/min recovered } \\
\text { in RNA }\end{array}$} & \multicolumn{3}{|c|}{$\begin{array}{l}\text { Residual RNA synthesis } \\
\text { (\% of control) }\end{array}$} \\
\hline & & $4 S$ & $18 S$ & $28 . S$ & $4 S$ & $18 S$ & $28 S$ \\
\hline & $h r$ & & & & & & \\
\hline Cultures infected with $50 \mathrm{PFU} /$ cell and & 0 & 6,900 & 0 & 0 & & & \\
\hline incubated for 15 min with $5 \mu \mathrm{c}$ of ${ }^{3} \mathrm{H}$ - & 2 & 6,000 & 0 & 0 & 88 & & \\
\hline uridine per $\mathrm{ml}$ at the indicated times & 5 & 4,100 & 0 & 0 & 60 & & \\
\hline Infected with 200 PFU and incubated & 0 & 12,450 & 15,450 & 14,000 & & & \\
\hline for $45 \mathrm{~min}$ with $5 \mu \mathrm{c}$ of ${ }^{3} \mathrm{H}$-uridine per & 2 & 10,000 & 7,000 & 6,550 & 80 & 45 & 47 \\
\hline $\mathrm{ml}$ & 5 & 4,900 & 4,100 & 3,500 & 40 & 26 & 25 \\
\hline Infected with 50 PFU and incubated for & 0 & $\mathbf{N M}^{b}$ & 26,000 & 37,300 & & & \\
\hline $\begin{array}{l}15 \text { min with } 7 \mu \mathrm{c} \text { of }{ }^{3} \mathrm{H} \text {-uridine per } \mathrm{ml} \\
\text { then } 1 \mathrm{hr} \text { with } 10^{-4} \mathrm{M} \text { cold uridine }\end{array}$ & 4 & NM & 13,950 & 19,400 & & 54 & 52 \\
\hline
\end{tabular}

"The methods used for the calculations are described in the legend to Fig. 1.

${ }^{b}$ Not measured.

leakage because of alteration of the nuclear membrane after infection cannot be ruled out, particularly in view of the data presented elsewhere in this paper that $4 S$ RNA leaks from infected cells beginning 4 to $5 \mathrm{hr}$ after infection.

(iii) The normalized specific activities of cytoplasmic and nuclear RNA of cells pulse-labeled 5 hr and later after infection were generally similar from one experiment to the next; however, the values for cells pulse labeled $2 \mathrm{hr}$ after infection varied by as much as $50 \%$ between experiments. This variation resulted from two causes. First, the uridine pool varied depending on the metabolic state of the cells. Cells fed 4 to $6 \mathrm{hr}$ before infection incorporated more ${ }^{3} \mathrm{H}$-uridine (and hence have a smaller uridine pool) than cells replenished with fresh medium 12 to $16 \mathrm{hr}$ before infection. Second, even though uninfected cells were treated in the same way as infected cells, the control inoculum was not identical to the one containing the virus. In consequence, the uridine pool in infected and uninfected cells varied somewhat during and shortly after infection.

Nuclear RNA. Replicate cultures, each containing approximately $2 \times 10^{6} \mathrm{HEp}-2$ cells, were infected at a multiplicity of 200 PFU and then exposed to ${ }^{3} \mathrm{H}$-uridine $(3 \mu \mathrm{c} / \mathrm{ml})$ at various times after infection (Fig. 4). The cells were then fractionated into nuclear and cytoplasmic fractions after lysing either by Dounce homogenization in RSB or by the use of Nonidet P-40. The nuclei were rinsed by centrifugation in RSB, lysed with $1 \%$ SDS in water, and homogenized by sonic treatment. The trichloroacetic acid-precipitable radioactivity (corrected for the recovery of optical density at $260 \mathrm{~nm}$ ) in the nuclei was then com- pared to that of uninfected control nuclei prepared in the same way. Figure 4 shows that the incorporation of radioactivity into the nucleus dropped rapidly after infection with herpesvirus. The data also show that nuclear RNA from cells disrupted mechanically had a lower specific ac-

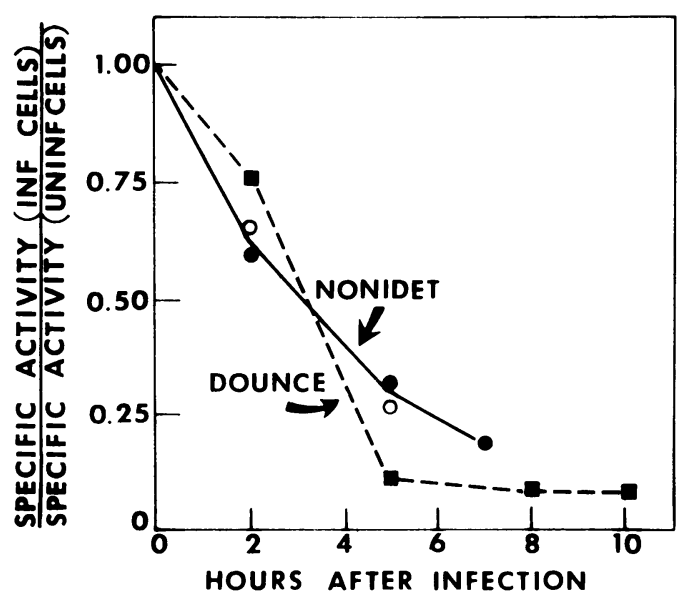

FiG. 4. Incorporation of radioactive uridine into the nuclei of herpesvirus-infected $\mathrm{HEp}-2$ cells. Cultures of $H E p-2$ cells were infected with a multiplicity of 200 $P F U$ of herpesvirus and incubated with $3 \mu c$ of ${ }^{3} \mathrm{H}$-uridine per $\mathrm{ml}$ for $20 \mathrm{~min}$ at various times after infection. The nuclei were isolated from cells lysed with Nonidet P-40 (circles) or by Dounce homogenization (squares), and the specific radioactivity was compared to uninfected control cultures. The open circles represent an experiment in which the nuclei were lysed with the high-salt buffer of Penman (15) and digested with deoxyribonuclease before assay for radioactivity. 
tivity than nuclear RNA from cells lysed by Nonidet P-40. This effect may be due, in part, to increased nuclear breakage at these times after infection (see above). It should be noted, however, that the nuclei from Dounce-homogenized cells contained two to three times more contaminating cytoplasmic rRNA than those obtained with Nonidet P-40; it could be expected that RNA extracted from nuclei contaminated with cytoplasm would have a lower specific activity than RNA extracted from clean nuclei.

In another series of experiments, the nuclei were lysed by the high-salt solution method of Penman (15), and the total nuclear RNA was extracted by the hot phenol-SDS method after deoxyribonuclease digestion. The results of this experiment were the same as those obtained with nuclei lysed by sonic treatment.

The size distribution of nuclear RNA in infected cells was determined in the following experiment. Approximately $3 \times 10^{-} \mathrm{HEp}-2$ cells were infected with a multiplicity of 100 PFU per cell. At $4.5 \mathrm{hr}$ after infection, the cells were incubated for $60 \mathrm{~min}$ in medium containing ${ }^{3} \mathrm{H}$-uridine $(5 \mu \mathrm{c} / \mathrm{ml})$ as described, and nuclear RNA was isolated and extracted along with the nuclear RNA from an identical uninfected culture of cells labeled for the same period. The nuclear RNA from both cultures was then centrifuged in sucrose density gradients. The optical density and radioactivity profiles are shown in Fig. 5. As mighit be expected from the results of experiments summarized in Fig. 3, the data show that at $4.5 \mathrm{hr}$ after infection there was virtually no ${ }^{3} \mathrm{H}$-uridine incorporated into $18 S$ and $28 S$ rRNA. However, an appreciable amount of RNA synthesized at this time had a high molecular weight $(>32 S)$ and a significant fraction of this RNA sedimented at $45 S$.

The continued synthesis in infected cells of $45 S$ RNA in the absence of synthesis of $18 S$ and $28 S$ rRNA raised two possibilities: (i) the $45 \mathrm{~S}$ nucleolar precursor RNA is not processed into $18 S$ and $28 S$ rRNA and ultimately degraded or (ii) the 45S RNA made in infected cells is a host or viral RNA unrelated to rRNA. To differentiate between these two possibilities, use was made of the fact that in the nucleus the methyl group of methionine is specifically incorporated into precursor rRNA $(10,27,32)$. A culture of $5 \times 10^{7}$ HEp-2 cells was infected with a multiplicity of 50 PFU per cell and incubated for $4 \mathrm{hr}$ in EMEM containing one-half the normal amount of methionine ( 0.05 instead of $0.1 \mathrm{~mm})$. A duplicate culture was mock-infected and incubated for the same time as an uninfected control. At $4 \mathrm{hr}$ after infection, the cells were incubated for $60 \mathrm{~min}$ in methionine-free EMEM containing $0.8 \mu \mathrm{c}$ of

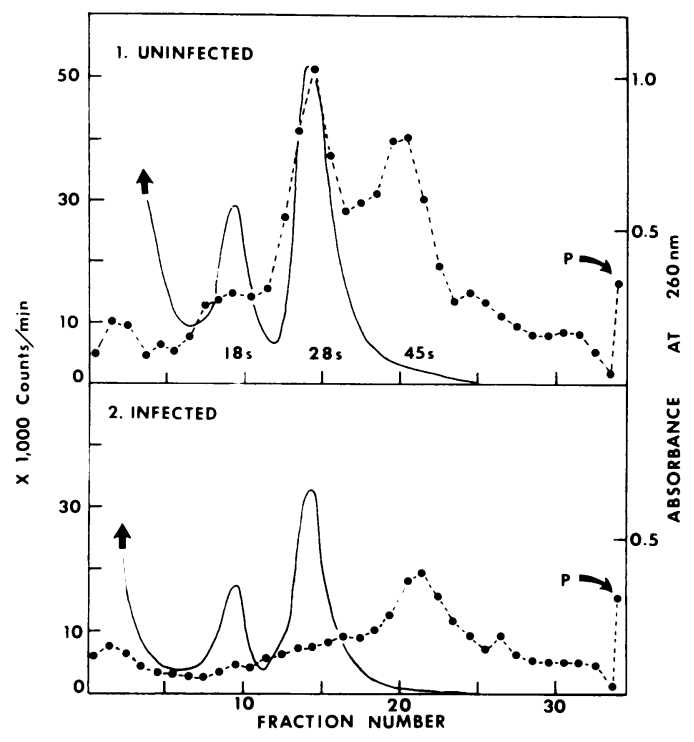

FIG. 5. Size distribution of nuclear RNA synthesized in HEp-2 cells infected with herpes simplex virus. Duplicate cultures of $3 \times 10^{7} \mathrm{HEp}-2$ cells were mockinfected (1) or infected with $100 \mathrm{PFU} /$ cell (2). After $4.5 \mathrm{hr}$ the cultures were incubated for $60 \mathrm{~min}$ in medium containing $5 \mu \mathrm{c}$ of ${ }^{3} \mathrm{H}$-uridine per $\mathrm{ml}$ and then harvested. The nuclei of the cells were isolated with Nonidet $P-40$, and the nuclear RNA was extracted by the hot phenolSDS method (21). The extracted nuclear RNA was precipitated with ethyl alcohol and centrifuged in an $0.5 \%$ SDS-15 to $30 \%(w / w)$ sucrose density gradient for $15 \mathrm{hr}$ at $25 \mathrm{C}$ and at $21,000 \mathrm{rev} / \mathrm{min}$ in a Spinco $S W 25.3$ rotor. The $1-\mathrm{ml}$ fractions were collected through a Gilford recording spectrophotometer. The $R N A$ was precipitated with trichloroacetic acid and as sayed for radioactivity. "P" marks the pellet at the bottom of the tube.

${ }^{14} \mathrm{C}$-methyl-methionine $(10 \mu \mathrm{c} / \mu$ mole $)$ and $2 \times$ $10^{-8}$ moles of adenosine and guanosine per $\mathrm{ml}$ of medium. At the end of the incubation period, the nuclei from the two cell cultures were isolated and the nuclear RNA was extracted and fractionated as described. The $45 S$ RNA synthesized in the infected cells was methylated (Fig. 6). It should be noted that in this experiment, which was done with cells infected at a lower multiplicity of infection than those used in the experiment summarized in Fig. 5, there was still some residual synthesis of $32 S$ to $28 S$ rRNA (10 to $15 \%$ of the control value), and, consequently, the level of synthesis of 45S RNA in these cells may be somewhat higher than that of cells infected at higher multiplicities (Fig. 5). Nevertheless, it is clear that the level of methylation of the 45S RNA synthesized in infected cells, at a time when the incorporation of radioactivity into $28 S$ and $18 S$ rRNA was virtually absent, was roughly that of 


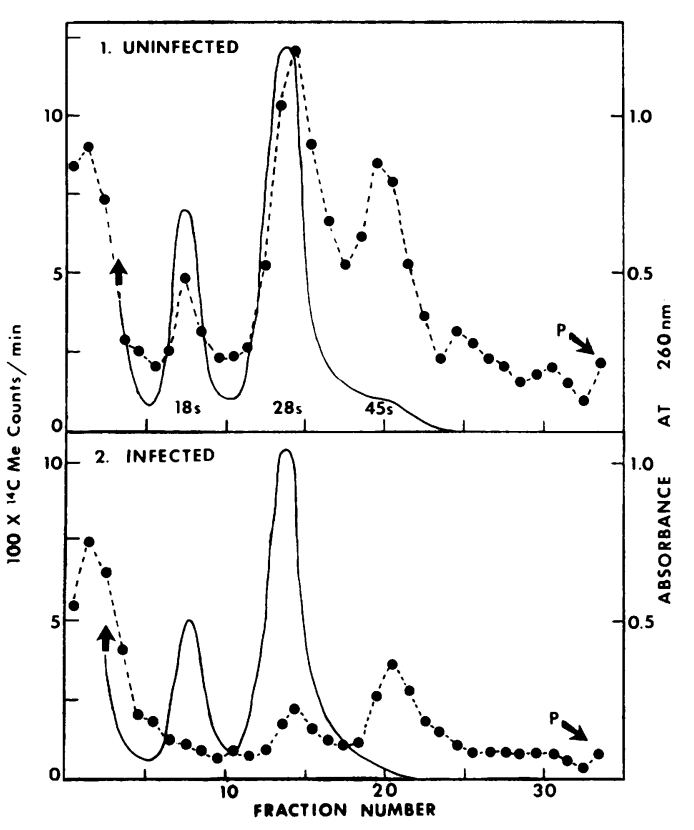

FIG. 6. Methylation of $45 S$ nuclear RNA synthesized in infected HEp-2 cells. Duplicate cultures of $5 \times 10^{7}$ cells were either mock-infected (1) or infected with a multiplicity of $50 \mathrm{PFU} /$ cell of herpesvirus (2). The cells were incubated for $4 \mathrm{hr}$ in EMEM containing $50 \%$ the normal amount of methionine and then for 60 min in methionine-free EMEM containing $0.8 \mu \mathrm{c}$ of ${ }^{14} \mathrm{C}$ methyl methionine per $\mathrm{ml}$ and $2 \times 10^{-4} \mathrm{M}$ unlabeled adenosine and guanosine. The isolation of nuclei and the extraction and fractionation of nuclear RNA were the same as described in the legend to Fig. 5. " $P$ " marks material found as a pellet at the bottom of the tube.

uninfected cells. This conclusion is based on the observation that the total radioactivity recovered under the 45S RNA peak in the nuclear RNA of the infected cells was approximately $30 \%$ of the control value (950 versus 2,800 counts $/ \mathrm{min}$ ), a proportion similar to that observed at a nearly comparable time after infection in the experiment summarized in Fig. 5.

In other experiments, we pulsed infected cells briefly with ${ }^{3} \mathrm{H}$-uridine and then chased them with actinomycin $\mathrm{D}$ to determine whether the $45 S$ RNA is stable or processed aberrantly. In one experiment, replicate cultures of $10^{7}$ cells were infected at a multiplicity of 80 PFU per cell and were exposed to ${ }^{3} \mathrm{H}$-uridine $(5 \mu \mathrm{c} / \mathrm{ml})$ for $20 \mathrm{~min}$ at $5 \mathrm{hr}$ after infection. Immediately $50 \%$ of the cells were harvested into ice-cold PBS, whereas the other $50 \%$ was incubated for an additional $45 \mathrm{~min}$ in medium containing actinomycin $\mathrm{D}(10 \mu \mathrm{g} / \mathrm{ml})$. The nuclear RNA was then extracted and centrifuged in sucrose density gradients along with nuclear RNA extracted from an uninfected control culture treated in the same way. The results showed the following. (i) The extract of infected cells pulsed with uridine but not chased yielded 27,000 counts/min, sedimenting in the region corresponding to $45 S$. (ii) RNA from infected cells pulsed and chased with actinomycin yielded 4,700 counts $/ \mathrm{min}$ in the $45 \mathrm{~S}$ region; moreover, there was no increase in radioactivity of the $18 S$ and $28 S$ RNA. (iii) In the uninfected control cells, about 65 to $70 \%$ of the original radioactivity was recovered in $45 S$ RNA ( 70,000 counts / min) after the pulse was "chased" out, with a concomitant increase in radioactivity in the $32 S$ to $28 S$ RNA region and the appearance of radioactivity in the $18 S$ rRNA. The results of this experiment indicate that the abortive processing of the 45S RNA in the infected cell nucleus results in its degradation into oligonucleotides sedimenting with $S$ values of less than $18 S$; but we cannot, at this time, determine whether the 45S RNA is degraded into mononucleotides.

Size distribution of virus-specific RNA. To determine the size distribution of nuclear and cytoplasmic RNA specified by the virus, $2 \times 10^{8}$ HEp-2 cells were infected with a multiplicity of $50 \mathrm{PFU}$ per cell and were labeled with ${ }^{3} \mathrm{H}$-uridine $(10 \mu \mathrm{c} / \mathrm{ml})$ for $1 \mathrm{hr}$ at $4.5 \mathrm{hr}$ after infection. The nuclei and cytoplasm were then separated with Nonidet P-40, and the nuclear RNA was extracted with hot phenol and SDS as described. The cytoplasmic extract was layered over $2 \mathrm{ml}$ of $50 \%$ RSB-sucrose and centrifuged at 60,000 $\mathrm{rev} / \mathrm{min}$ for $2.5 \mathrm{hr}$ in a Spinco 65 rotor. The pellet which contained the cytoplasmic polyribosomes, only about $25 \%$ of the $74 S$ ribosomes, and little or no low-molecular-weight RNA (Wagner and Roizman, unpublished data) was suspended in $1 \mathrm{ml}$ of SDS buffer. Both the nuclear RNA and cytoplasmic polyribosomal RNA were then centrifuged in sucrose density gradients (Fig. 7). The fractions were pooled as shown in Fig. 6 and were precipitated with ethyl alcohol. The precipitates were then resuspended in $2 \mathrm{ml}$ of RSB, digested for $45 \mathrm{~min}$ with $100 \mu \mathrm{g}$ of electrophoretically purified deoxyribonuclease, phenolextracted again, and reprecipitated with ethyl alcohol. The precipitated RNA was collected by centrifugation and then dissolved in $4 \times \mathrm{SSC}$; portions were incubated for $20 \mathrm{hr}$ at $67 \mathrm{C}$ with $2 \mu \mathrm{g}$ of herpesvirus DNA on membrane filter discs (Millipore Corp.) as described.

Virus-specific RNA heavier than $28 S$ was found in the nucleus and in the polyribosome pellet (Table 2). In the nucleus, there was virusspecific RNA with $S$ values greater than $50 S$, and the percentage of this RNA annealing to viral DNA was higher than that of more slowly 


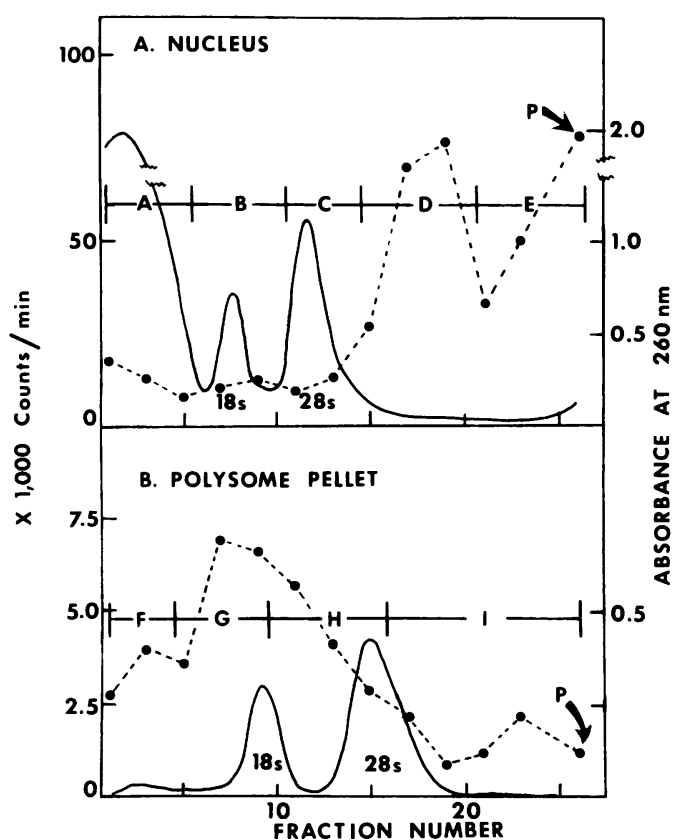

FIG. 7. Sucrose density gradient fractionation of nuclear and cytoplasmic RNA from infected $H E p-2$ cells. Replicate cultures totaling $2 \times 10^{8} \mathrm{HEp}-2$ cells were infected with a multiplicity of 50 PFU/cell. At 4.5 hr after infection, the cells were pulse-labeled for 60 min in medium containing $10 \mu \mathrm{c}$ of ${ }^{3} \mathrm{H}$-uridine per $\mathrm{ml}$. The nuclei and cytoplasm were separated with $0.5 \%$ Nonidet P-40 in RSB followed by low-speed centrifugation. (A) Nuclear RNA was extracted with hot phenol and $S D S$, precipitated with ethyl alcohol, redissolved, and centrifuged in an $0.5 \%$ SDS-15 to $30 \%(\mathrm{w} / \mathrm{w})$ sucrose density gradient for $16 \mathrm{hr}$ at 20,000 rev/min in the Spinco SW25.1 rotor. Fractions $(1.25 \mathrm{ml})$ were collected through a Gilford recording spectrophotometer, and 0.1-ml samples from every other fraction were precipitated with trichloroacetic acid and assayed for radioactivity. The total radioactivity per fraction was calculated and plotted as shown, pooled as shown, and precipitated with ethyl alcohol. $(B)$ The polyribosomal $R N A$ pellet was obtained by centrifugation of cytoplasmic extract at $60,000 \mathrm{rev} / \mathrm{min}$ for $2.5 \mathrm{hr}$ through a $2-\mathrm{ml}$ pad of $50 \%(w / w)$ sucrose in RSB; it was dissolved in $1.5 \mathrm{ml}$ of SDS buffer and centrifuged in an $0.5 \%$ SDS15 to $30 \%(w / w)$ sucrose density gradient at 22,000 $\mathrm{rev} / \mathrm{min}$ for $16 \mathrm{hr}$ in the Spinco SW25.1 rotor. Samples of every other fraction were precipitated with trichloroacetic acid and assayed for radioactivity. Fractions were pooled as indicated. " $P$ " denotes the pellet at the bottom of the centrifuge tubes.

sedimenting RNA. The amounts of DNA used in this experiment $(2 \mu \mathrm{g} / \mathrm{disc})$ made it impossible to determine the absolute amounts of viral RNA of various sizes found in the nucleus and cytoplasm. Flanagan (11) showed that the synthesis of RNA annealable to cellular DNA in cells
TABLE 2. Size distribution of nuclear and cytoplasmic RNA specified by herpes simplex virus in HEp-2 cells

\begin{tabular}{l|c|r|r|r}
\hline Source & $\begin{array}{c}\text { Frac- } \\
\text { tion } \\
\text { (Fig. 7) }\end{array}$ & $\begin{array}{r}\text { Approx } \\
\text { sedimen- } \\
\text { tation } \\
\text { coeffi- } \\
\text { cient (S) }\end{array}$ & $\begin{array}{r}\text { 3H counts/ } \\
\text { min incu- } \\
\text { bated with } \\
\text { herpesvirus } \\
\text { DNA }\end{array}$ & $\begin{array}{c}\text { Ribonuclease- } \\
\text { resistant } 8 \mathrm{H} \\
\text { counts/min } \\
\text { bound to her- } \\
\text { pesvirus DNA } \\
(2 \mu \mathrm{g})\end{array}$ \\
\hline Nucleus & $\mathrm{A}$ & $4-12$ & 100,000 & $300(0.3)^{a}$ \\
& $\mathrm{~B}$ & $12-24$ & 52,000 & $240(0.65)$ \\
& $\mathrm{C}$ & $24-32$ & 61,000 & $310(0.5)$ \\
Polyribo- & $\mathrm{D}$ & $32-50$ & 82,000 & $250(0.3)$ \\
Some pel- & $\mathrm{F}$ & $>50$ & 53,000 & $450(0.85)$ \\
let & $\mathrm{G}$ & $10-19$ & 11,700 & $130(1.1)$ \\
& I & $19-28$ & 10,500 & $95(0.95)$ \\
& I & $>28$ & 8,300 & $50(0.6)$ \\
\hline
\end{tabular}

${ }^{a}$ Numbers in parentheses expressed as per cent.

pulse-labeled for $15 \mathrm{~min}$ at 4 to $8 \mathrm{hr}$ after infection continued at $50 \%$ the rate of synthesis of RNA in uninfected cells. With this short a period of labeling most of the RNA synthesized would be nuclear. We also found that, in cells labeled from 6 to $7 \mathrm{hr}$ after infection, the proportion of nuclear RNA annealable to cellular DNA, under the same conditions as those used for annealing RNA to viral DNA, decreased to about $50 \%$ of that of uninfected controls. These data and the fact that the $45 S$ ribosomal precursor RNA continued to be synthesized in uninfected cells suggest that not all, or even necessarily a large part, of the radioactivity found in any of the regions of the nuclear and cytoplasmic gradients may be virus-specific. A rough measure of the relative abundance of viral RNA of different sedimentation coefficients may be made on the basis of (i) the assumption that species of viral RNA of different sizes have approximately the same specific radioactivity and anneal with the same efficiency to DNA and (ii) the observation that the amount of nuclear RNA used in the hybridization experiments was in each case well below the saturation level for the amount of DNA used, as shown by the finding that the addition of two to three times the amount of radioactive RNA did not result in a decreased percentage of radioactivity bound to viral DNA. On that basis the region of the gradient containing the most rapidly sedimenting nuclear RNA ( $>50 S$ ) has a relatively higher proportion of viral RNA than the regions containing more slowly sedimenting nuclear RNA. As expected from the results shown in the preceding section, the relative proportion of viral RNA in the region of the gradient containing $32 S$ to $50 S$ material was 
considerably lower than that in all except the most slowly sedimenting material. Thus, we conclude that the bulk of the $32 S$ to $50 S$ material made in infected cells consists of precursor rRNA.

The small amounts of radioactivity recovered in the various regions of the SDS-sucrose density gradient after centrifugation of RNA extracted from the polyribosomal pellets precluded saturation studies, but it seems reasonable to assume that the amounts of RNA used to anneal with viral DNA, here too, were well below saturation. In this case, the RNA containing the highest relative proportion of virus-specific RNA is in the region of 10 to $19 S$, in contrast to the case with the nuclear RNA. The fact that there is at least some viral RNA found in the polyribosome pellet sedimenting more rapidly than $28 \mathrm{~S}$ suggests that either (i) there are some large species of viral mRNA with molecular weights in the range of $1.5 \times 10^{6}$ to $2 \times 10^{6}$ or (ii) some rapidly sedimenting RNA leaks from the nucleus and co-sediments with the polyribosomes. In regard to the second possibility, it was noted above that high-molecular-weight RNA in the cytoplasm may be nuclear RNA which "leaks" through the virus-modified nuclear membrane after lysis of the cells with Nonidet P-40.

Leakage of RNA from infected cells. Earlier studies from this laboratory $(16,20)$ showed that membranes of cells infected with herpesviruses become modified after infection. A property of the modified membranes is that they leak macromolecules from the cell into the extracellular fluid (13). The question arose as to whether the decrease in yield of RNA and particularly in $4 S$ RNA seen in Fig. 1 might be due to leakage from the cells into the extracellular fluid. To determine whether there was leakage, replicate cultures, each containing $2 \times 10^{6} \mathrm{HEp}-2$ cells, were infected with a multiplicity of 20 PFU per cell and were exposed to $5 \mu \mathrm{c}$ of ${ }^{3} \mathrm{H}$-uridine per $\mathrm{ml}$ for 30 min at $2,5,7$, and $9 \mathrm{hr}$ after infection, respectively.

The cultures were rinsed with warm maintenance medium containing $10^{-4} \mathrm{M}$ unlabeled uridine and then were incubated for an additional $30 \mathrm{~min}$ in more of this medium. At this time, the cells were harvested and the medium was assayed for trichloroacetic acid-precipitable radioactivity before and after digestion with $100 \mu \mathrm{g}$ of pancreatic ribonuclease per $\mathrm{ml}$ for $30 \mathrm{~min}$ at $37 \mathrm{C}$. The amount of trichloroacetic acid-precipitable radioactivity remaining after ribonuclease treatment was less than $1 \%$ of the original amount, and the difference between the two was defined as extracellular RNA. The cells were then homogenized by sonic treatment in water, and intracellular trichloroacetic acid-precipitable RNA was determined in the same manner. The ratio of extracellular to intracellular RNA at various times after infection was determined. There was a two- to threefold increase in extracellular RNA by $5 \mathrm{hr}$ after infection (Fig. 8).

Another possible reason for the lowered recovery of $4 S$ RNA after herpesvirus infection would be a selective degradation of pre-existing $4 S$ RNA. This was shown not to be the case in the following experiment. Cultures of approximately $5 \times 10^{6} \mathrm{HEp}-2$ cells were incubated for $30 \mathrm{~min}$ in medium containing $10 \mu \mathrm{c}$ of ${ }^{3} \mathrm{H}$-uridine per $\mathrm{ml}$ and then again for an additional $4 \mathrm{hr}$ in medium containing $10^{-4} \mathrm{M}$ unlabeled uridine. At this time, some of the cultures were infected at a multiplicity of 50 PFU. Cultures were harvested at 6,12 , and $24 \mathrm{hr}$ after infection, and the cytoplasmic RNA was subjected to polyacrylamide gel electrophoresis as described in the legend to Fig. 1. In all cases, the specific activity of the $4 S$ RNA from the infected cells was the same as that of uninfected cells treated the same way, although by $24 \mathrm{hr}$ after infection the recovery of $4 S$ RNA was $20 \%$ or less than that of control cultures.

\section{DISCUSSION}

This paper describes the overall pattern of RNA synthesis in infected cells. Three particular aspects are discussed here.

Inhibition of rRNA synthesis. As pointed out in the introduction, earlier studies on whole cell extracts of infected cells labeled for short intervals at various times after infection showed a general

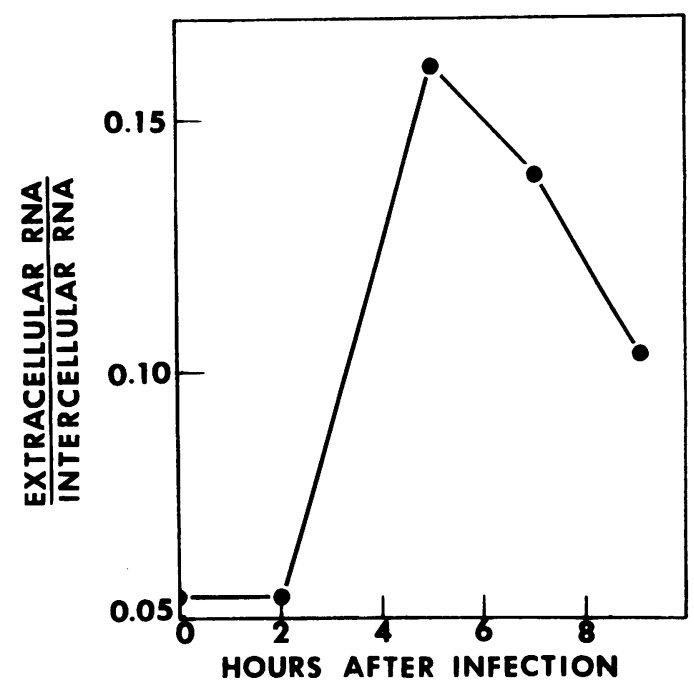

FIG. 8. Leakage of $R N A$ from $H E p-2$ cells infected with herpesvirus. Cultures of $\mathrm{HEp}-2$ cells were infected and labeled with ${ }^{3} \mathrm{H}$-uridine; the extracellular RNA and intracellular RNA were determined as described. 
rapid decline in the synthesis of both highmolecular-weight RNA and rRNA $(8,11)$. By fractionating the cell into nuclear and cytoplasmic fractions and by labeling cells for longer intervals, we were able to examine the inhibition of rRNA synthesis in some detail. It is interesting that by 4 to $5 \mathrm{hr}$ after infection, when $28 S$ and $18 S$ rRNA synthesis is reduced by $90 \%$ or more, there is still synthesis and methylation of $45 S$ rRNA precursor at at least $30 \%$ of uninfected control values. It is clear that the inhibition of rRNA synthesis following herpesvirus infection is caused by two complimentary processes: (i) inhibition of the rate of synthesis of $45 S$ ribosomal RNA precursor and (ii) a decrease in the rate of processing of the 45S RNA that is synthesized. The fact that this was not previously reported might be due to the short labeling intervals used in earlier studies $(8,11)$; indeed, the sucrose density gradient profiles of RNA extracted from cells at comparable times after infection, as reported by Hay et al. (11) and Flanagan (8), do show the synthesis of some high-molecular-weight material although $45 S$ RNA cannot be resolved.

The abortive processing of the $45 S$ rRNA precursor coincides with the teginning of disaggregation of infected cell nucleoli (Schwartz, Roizman, and Sydiskis, in preparation). It seems probable that there is a relationship between the abortive processing of $45 S$ RNA and nucleolar disaggregation; however, the mechanistic nature of the relationship is not clear.

It is of interest to compare the two-stage inhibition of rRNA synthesis in herpesvirus-infected cells with that occurring in cells infected with poliovirus or in those treated with vinca alkaloids. In the poliovirus-infected cells, the net synthesis of $45 S$ RNA is gradually reduced in rate. However, while it is made, the 45S RNA is processed normally, but the processing of $32 S$ RNA into 28S RNA is abortive as is the transport of $28 S$ rRNA into the cytoplasm (5). In cells exposed to high levels of the vinca alkaloid vinblastine sulfate, the decrease in the synthesis of rRNA is accompanied by a preferential decrease in the rate of the transfer of 28S rRNA into the cytoplasm as compared with the $18 S$ RNA (28).

Another point of interest is the residual synthesis (less than $10 \%$ ) of $28 S$ and $18 S$ rRNA in cells infected at high multiplicities even as late as 7 to $9 \mathrm{hr}$ after infection (Fig. 1). The fraction of residual synthesis is similar to that of residual DNA synthesis encountered in other studies (Schwartz et al., in preparation). We cannot say whether the small amount of residual host nucleic acid synthesis reflects lack of inhibition of host macromolecules in 5 to $10 \%$ of the cells or whether it reflects incomplete inhibition of host nucleic acid synthesis in all cells. It should be noted, however, that immunofluorescence studies carried out on cultures infected at these multiplicities indicate that better than $99 \%$ of cells contain viral antigens (Roizman, unpublished data)

Inhibition of 4S RNA synthesis. We have no explanation at present for the differential rate of inhibition of $4 S$ RNA and rRNA synthesis. It was noted in the introduction that Subak-Sharpe and co-workers $(11,23,24)$ have suggested that herpes simplex virus directs the synthesis of some species of tRNA. The residual synthesis of $4 S$ RNA in infected cells, even at its lowest levels (approximately $20 \%$ of uninfected control values), is sufficient to account for several hypothetical species of virus-specified tRNA. The fact that $4 S$ RNA synthesis is inhibited to such a large extent implies that most of the cellular tRNA species are present in sufficient levels for the production of virus proteins.

Size distribution of RNA specified by herpes simplex virus. We are currently engaged in further studies on the synthesis and function of the highmolecular-weight RNA specified by the virus and found in the nucleus of infected cells, but two points should be made here. First, the finding of large species of RNA in the nucleus and of much smaller species in the cytoplasmic polyribosome fraction suggests that either the highmolecular-weight viral RNA in the nucleus serves some function other than mRNA on polyribosomes or that it must be cleaved before it becomes associated with ribosomes.

The fact that Flanagan (8) did not find a high percentage of high-molecular-weight, virusspecific RNA requires some comment. It is not clear what the fraction of RNA he defined as $32 S$ was, since no profiles of the sucrose density gradient fractionation of the whole cell extracts were given; therefore, this fraction may contain RNA of considerably higher molecular weight. Also, the fact that his annealing experiments were carried out at $61 \mathrm{C}$ opens the possibility that his estimates of the amounts of viral RNA of various sizes may not be accurate. It should be pointed out here that Flanagan was unable to show the presence of significant amounts of virusspecific RNA sedimenting in the range of $4 S$ to $12 S$, in contrast to the results reported here and also in contrast to the results of Subak-Sharpe and co-workers $(23,24)$. Also, in our experiments, a temperature of $61 \mathrm{C}$ resulted in a considerable decrease in the amount of RNA-DNA hybrids formed (Wagner and Roizman, unpublished data), although our method of hybridization is somewhat different from that of Flanagan. 


\section{ACKNOWLEDGMENTS}

This investigation was supported by Public Health Service grant CA 08494 from the National Cancer Institute, American Cancer Society grant E 314E, and National Science Foundation grant GB 8242. One of us (E.W.) is a postdoctoral fellow of the Helen Hay Whitney Foundation.

We thank Virginia Fano for excellent technical help with part of this work and especially Steven Bachenheimer for carrying out the experiments on the decay of $4 S$ RNA in infected and uninfected cells.

\section{LITERATURE GITED}

1. Aurelian, L., and B. Roizman. 1965. Abortive infection of canine cells by herpes simplex virus. II. The alternative suppression of synthesis of interferon and viral constituents. J. Mol. Biol. 11 :539-548.

2. Ben-Porat, T., and A. S. Kaplan. 1965. Mechanism of inhibition of cellular DNA synthesis by pseudorabies virus. Virology 25:22-29.

3. Borun, T., M. Schraff, and E. Robbins. 1967. Preparation of mammalian polyribosomes with the detergent Nonidet P-40. Biochim. Biophys. Acta 149:302-304.

4. Darnell, J. E., Jr. 1968. Ribonucleic acids from animal cells. Bacteriol. Rev. 32:262-290.

5. Darnell, J., M. Girard, D. Baltimore, D. Summers, and J. Maizel. 1967. The synthesis and translation of poliovirus RNA, p. 375-402. In J. Colter (ed.), Proc. Symp. Mol. Biol. Viruses, Alberta, Canada. Academic Press, Inc., New York.

6. Dulbecco, R., and M. Vogt. 1954. Plaque formation and isolation of pure lines with poliomyelitis viruses. J. Exp. Med 99:167-182.

7. Eagle, H. 1959. Amino acid metabolims in mammalian cell cultures. Science 130:432-437.

8. Flanagan, J. F. 1967. Virus-specific ribonucleic acid synthesis in $\mathrm{KB}$ cells infected with herpes simplex virus. J. Virol. 1: 583-590.

9. Gillespie, D., and S. Spiegelman. 1965. A quantitative assay for DNA-RNA hybrids with DNA immobilized as a membrane. J. Mol. Biol. 12:829-842.

10. Greenberg, H., and S. Penman. 1966. Methylation and processing of ribosomal RNA in HeLa cells. J. Mol. Biol. 21 :527536.

11. Hay, J., G. J. Koteles, H. M. Keir, and H. Subak-Sharpe. 1966. Herpesvirus specified ribonucleic acids. Nature 210: 387-390.

12. Hay, J., H. Subak-Sharpe, and W. Sheperd, 1967. New transfer ribonucleic acid in BHK-21/C13 cells infected with herpesvirus. Biochem. J. 103:69.

13. Kamiya, T., T. Ben-Porat, and A. S. Kaplan. 1965. Control of certain aspects of the infective process by progeny viral DNA. Virology 26:577-589.

14. O'Callaghan, D. J., W. Cheevers, G. Gentry, and C. C. Randall. 1968. Kinetics of cellular and viral DNA synthesis in equine abortion (herpes) virus infection of L-M cells. Virology 36:104-114.
15. Penman, S. 1966. RNA metabolism in the HeLa cell nucleus. J. Mol. Biol. 17:1 17-130.

16. Roizman, B. 1962. Polykaryocytosis. Cold Spring Harbor Symp. Quant. Biol. 27:327-342.

17. Roizman, B., and L. Aurelian. 1965. Abortive infection of canine cells by herpes simplex virus. I. Characterization of viral progeny from cooperative infection with mutants differing in their capacity to multiply in canine cells. J. Mol. Biol. 11 :528-538.

18. Roizman, B., G. Borman, and M. Kamali-Rousta. 1965. Macromolecular synthesis in cells infected with herpes simplex virus. Nature 206:1374-1375.

19. Roizman, B., and P. G. Spear. 1968. Preparation of herpes simplex virus of high titer. J. Virol. 2:83-84.

20. Roizman, B., and S. Spring. 1967. Alteration in immunologic specificity of cells infected with cytolytic viruses, p. 85-96. In J. J. Trentin (ed.), Proc. Conf. Cross Reacting Antigens and Neoantigens. Williams \& Wilkins Co., Baltimore.

21. Scherrer, K., and J. E. Darnell. 1962. Sedimentation characteristics of rapidly labeled RNA from HeLa cells. Biochem. Biophys. Res. Commun. 7:486-490.

22. Spring, S., and B. Roizman. 1968. Herpes simplex virus prod ucts in productive and abortive infection. III. Differentiation of infectious virus derived from nucleus and cytoplasm with respect to stability and size. J. Virol. 2:979-985.

23. Subak-Sharpe, H., and J. Hay. 1965. An animal virus with DNA of high guanine and cytosine content which codes for SRNA. J. Mol. Biol. 12:924-928.

24. Subak-Shapre, H., W. M. Shepherd, and J. Hay. 1966. Studies on sRNA coded by herpesvirus. Cold Spring Harbor Symp. Quant. Biol. 31 :583-594.

25. Sueoka, N., and T-Y. Cheng. 1962. Fractionation of nucleic acids with the methylated albumin column. J. Mol. Biol. 4:161-172.

26. Sydiskis, R., and B. Roizman. 1966. Polyribosomes and protein synthesis in cells infected with a DNA virus. Science 153:76-78.

27. Wagner, E.. S Penman, and V. Ingram. 1967. Methylation patterns of HeLa cell ribosomal RNA and its nucleolar precursors. J. Mol. Biol. 29:371-388.

28. Wagner, E., and B. Roizman. 1968. The effect of the vinca alkaloids on RNA synthesis in human cells in vitro. Science 162:569-570.

29. Warner, J., P. Knopf, and A. Rich. 1963. A multiple ribosoma 1 structure in protein synthesis. Proc. Nat. Acad. Sci. U.S.A. 49:122-129.

30. Weinberg, R., U. Loening, M. Willems, and S. Penman. 1967. Acrylamide gel electrophoresis of HeLa cell nucleolar RNA. Proc. Nat. Acad. Sci. U.S.A. 58:1088-1095.

31. Weiss, S. B., W.-T. Hsu, J. Foft, and N. Scherberg. 1968. Transfer RNA coded by the T4 bacteriophage genome. Proc. Nat. Acad. Sci. U.S.A. 61 :114-121.

32. Zimmerman, E. F., and B. Holler. 1967. Methylation of $45 S$ ribosomal RNA precursor in HeLa cells. J. Mol. Biol. 23:149-162. 